\title{
What grounds special treatment between siblings?
}

\author{
Marcus William Hunt \\ Department of Philosophy, School of Liberal Arts, Tulane University, U.S.A, \\ mhunt4@tulane.edu
}

DOI: http://dx.doi.org/10.5324/eip.v14i1.3362

(cc) BY

This is an open access article distributed under the terms of the Creative Commons Attribution 4.0 International License, which permits unrestricted use, distribution, and reproduction in any medium, provided the original author and source are credited.

Siblings ought to treat one another specially - in other words, siblings qua siblings ought to treat one another in ways that they need not treat others. This paper offers a theory of why this is the case. The paper begins with some intuitive judgments about how siblings ought to treat one another and some other normative features of siblinghood. I then review three potential theories of why siblings ought to treat one another specially, adapted from the literature on filial piety: the gratitude theory, the friendship theory, and the special goods theory. In each case, these theories fail to explain some of the intuitive judgments about how siblings ought to treat one another. The paper then proposes a familial belonging theory. The institution of the family has certain goals, which impose normative demands on family members. I suggest that one such family goal is that every member feel familial belonging towards every other member, a goal which grounds the ways in which siblings ought to treat one another specially.

Keywords: family ethics, filial piety, friendship, gratitude, sibling

\section{Introduction}

Siblings ought to treat one another specially - siblings qua siblings ought to treat one another in ways that they need not treat others. This paper aims to give a theory of why siblings ought to treat one another specially. The paper begins by offering a rough characterization of the special ways in which siblings ought to treat one another and of some other normative features of siblinghood. With this characterization in mind, we will be better able to assess answers to the "why" question. So far as I am aware, no contemporary philosophical literature on the question of what grounds special treatment between siblings is available. Therefore, this paper investigates whether extant theories of why children ought to treat their parents specially (theories of "filial piety") serve as good models for understanding why siblings should give each other special treatment, and I suggest that they do not. The extant theories are the gratitude theory, the friendship theory, and the special goods theory. I then turn to outlining my own theory, the familial belonging 
theory. This theory postulates that the institution of the family has a particular goal, which is that every member should feel familial belonging towards every other member. The special ways in which siblings ought to treat one another are grounded in this goal, and can help siblings avoid frustration of this goal and facilitate its achievement.

First I offer some clarifications. In a prototypical case, siblings ought to treat one another specially for a wide variety of possible reasons -gratitude, friendship, love, because they can provide special goods to one another, or to promote feelings of familial belonging. In this paper, the normative and axiological richness of prototypical sibling relationships will be bracketed for the purpose of addressing the question of why siblings owe things to one another qua sibling. The paper is concerned with which of these normative sources is the one that pertains between siblings qua siblings and can explain the basic contours of how siblings ought to treat one another specially, rather than a normative source that often develops in the context of siblinghood. I will not attempt an analytic definition of the term sibling, trusting that such definitions will prove elusive and trusting that we are all familiar with prototypical cases. The terms sibling, child, parent and family will be used in their moral rather than biological senses (without taking a stand either way on the moral significance of biological ties) throughout this paper. Lastly, I will not provide an account of the conditions under which, if at all, someone ceases to be a sibling or a parent, nor assume any particular account of how siblinghood or parenthood are acquired.

\section{The intuitive data}

I begin with some of my intuitive judgments about the special ways that adult siblings ought to treat one another and some other normative features of siblinghood. Beginning with one's own intuitive judgments may arouse the suspicion of being idiosyncratic. This is a reasonable suspicion, but given that existing philosophical discussion of siblinghood is so scarce, and since there is no stock set of intuitive judgments on which to draw, this seems to be where our starting point must be. The main desiderata of a good theory for what grounds special treatment between siblings will be that it explains these intuitive judgments.

- Content. Here is a list of the special ways that adult siblings ought to treat one another:

- Continuation of the relationship. Adult siblings often do not have very intimate relationships (LaFollette 2017). Frequently, they do not spend much time with one another or share their everyday troubles. There seems to be nothing (normatively) wrong with this, even though intimacy between adult siblings is (axiologically) good. Adult siblings should continue in the less intimate relationships that they do share - such as making an effort to attend family reunions, talking every so often, and letting each other know about significant life events, rather than becoming entirely estranged.

- Cooperation in discharging duties of filial piety. It seems that adult children have duties of filial piety to their parents, such as to provide care and companionship in the parents' old age. Siblings ought to help cooperate in discharging these duties, e.g. discussing their parents' well-being with one 
another, making care decisions together, coordinating their visits to their parents so that they do not go without company for too long. Or again, if a sister ends up being the one who spends the most time caring for an elderly parent - because her siblings live in a different part of the country, for example - the siblings ought to give her financial compensation for this. Even though the sister owes it to her parents that she look after them in the event that her siblings fail to compensate her financially, she would have a rightful complaint against them that they were not only bad children but bad siblings for failing to do so.

- Material help in cases of severe material need. Siblings ought to give material help to a sibling who is in severe material need, e.g. paying for their groceries if they are going hungry, letting them stay in the spare room if they have become homeless. In cases other than severe material need, the normative impetus towards material help drops off sharply - more prosperous siblings are not doing something wrong if they do not help a less prosperous sibling with a deposit on a house.

- Offering and receiving advice. Siblings ought to offer advice to and receive advice from one another about various aspects of their lives. This tentatively extends even to unsolicited advice - in a manner somewhat similar to parents, siblings ought to offer advice and hear one another's advice even when it is unasked for (and even when a sibling would rather not hear it; telling one another "home truths").

○ Relationship with their children. Siblings ought to have relationships with their nieces and nephews. This might involve buying the nieces and nephews birthday presents, developing shared interests with them (say, a love of maps and geography or teaching them origami or woodwork), spending time with them, taking them on day-trips. If a sibling displayed a total lack of interest in having a relationship with one's children, one could rightly regard them as being a bad sibling as well as a bad uncle or aunt. Likewise, if a sibling did not allow such relationships to develop - by never bothering to help arrange visits or ridiculing a shared interest, for example - one could rightly regard them as a bad sibling.

- Non-discretionary. Siblings do not choose to be siblings, and they cannot choose not to be siblings. These descriptive facts about the sibling relationship also apply to the normative question of how siblings ought to treat one another. Siblings do not choose or incur by their choices a significant portion of how they ought to treat one another, nor can they choose to rid themselves of these oughts. By way of example, if my sister and I tried to agree that we would not help one another in cases of severe material need, and in the event that my sister did fall into severe material need, she might rightly say that what we had tried to agree to had not really altered how I ought to treat her.

- Open-ended. There is no type of action by which one can, once and for all, finish giving a sibling all the special treatment owed them, nor is there a time period after which one no longer ought to treat a sibling specially.

- Permanent regret in cases of breakdown. As noted, relationships between siblings are often not intimate, and siblings can become estranged by a long lapse of contact. But, beyond this, relationships between siblings can break down into mutual hostility. Two brothers who refuse to go back to their parents' home for 
Christmas if the other will be there; who complain to their parents about the other, or who ask their sister for gossip about the other's failings are examples of such behavior. In cases where the relationship between siblings breaks down, both ought to regard this with regret permanently. If the relationship between you and your sibling broke down 20 years ago you ought to still regret this, whereas if you had a boyfriend or a co-worker 20 years ago you need not any longer regret that those relationships broke down into mutual hostility.

- Permanently reduced well-being in cases of breakdown. As a descriptive claim rather than a normative claim, a relationship between siblings that breaks down permanently reduces the well-being of both so long as the breakdown continues. The relationship with your sibling that has been broken down for 20 years continues to reduce your well-being, whereas your relationship with an old boyfriend that has been broken down for 20 years does not continue to reduce your well-being - it might only have reduced your well-being for a few months.

- Repair. If the relationship between siblings breaks down, both siblings ought to make attempts to repair it. For instance, if one sibling has wronged the other by stealing from them and this has led to a breakdown in their relationship, both siblings ought to make attempts at repairing it. This seems to be a somewhat unusual feature in how siblings ought to treat one another specially. In many other cases a normative impetus to repair a relationship is absent, or falls only or overwhelmingly on the party to blame for the breakdown.

- Robust. The special treatment due between siblings is not easily changed or diminished by the wrongdoing of either. If my brother embarks on a life of crime and even wrongs me as a result, or if he fails to treat me in the special ways that a sibling ought to, there is still some special treatment I ought to give him, even if the treatment I ought to give him is somewhat changed or diminished. The sibling relationship is not maximally robust - Mussolini's sister need not have continued to send him birthday cards or invited him to visit his nieces and nephews - and plausibly is not as robust as the attitude of parents towards their child, but compared to many other relationships the sibling relationship is highly robust. In a similar vein, the special treatment that siblings ought to give one another is not easily changed or diminished by behavior that either party regards as negative in value - e.g. if my brother joins a religion I dislike or votes for the party I dislike or develops character traits I dislike or lives a lifestyle I dislike, I still owe him special treatment in certain ways. "He's still my brother" is a normative as well as descriptive claim.

I note that these remarks apply, mutatis mutandis, to how siblings ought to treat one another during childhood. A sibling's sense of how they ought to treat their sibling ought not be excessively disturbed by the sibling's wrongdoings (a parent might say "I know he deleted all your saves on Super Mario, I know he rifled through your private things, but..."), siblings ought to try to repair problems in their relationship, siblings ought to regard the demands of siblinghood as openended (a parent might say "I know you really helped him with tidying up the garden last week, but could you also help him with..."). Again, siblings ought to offer advice about life ("Don't listen to those bullies, I was scared when I started at a new school too"), and siblings ought to help one another care for their parents ("I bought mom the chocolates, so you make the card"). 


\section{Theories drawn from the literature on filial piety}

Drawing from the literature on filial piety, I now outline and critique three potential theories of what grounds special treatment between siblings.

\section{The gratitude theory}

When someone benefits you, they are your benefactor. It is typically fitting to feel gratitude to one's benefactor and unfitting not to. In turn, gratitude constitutively has certain desires such as a desire to benefit one's benefactor - a "desire to make a return" (Walker 1981: 49). The gratitude theory of filial piety says that since parents act as benefactors to their children, children ought to feel gratitude to their parents and so ought to desire to benefit their parents. In this way, children incur a "debt of gratitude" (Blustein 1982: 175) to their parents.

Plausibly, siblings usually benefit one another in the ordinary course of life as children and as adults, and so we would expect to find debts of gratitude as a normative source in sibling relationships. Yet, it seems that debts of gratitude are not what accounts for the basic contours of how siblings qua siblings ought to treat one another specially because debts of gratitude are not able to explain many of the intuitive judgments noted above, most importantly:

- Non-discretionary. Debts of gratitude can be waived by the person to whom they are owed. Some siblings might be "uncomfortable with or uninterested in displays of gratitude" (Keller 2006: 259), yet special treatment still ought to be given them.

- Open-ended. Debts of gratitude are not open-ended (Keller 2006: 260-62), e.g. if I am grateful to my old boss for the astounding reference letter that she wrote for me, I may pay off my debt of gratitude by writing her a thoughtful thank you letter and buying her a bottle of wine.

- Robust. Debts of gratitude are not robust. Consider the case of a benefactor to whom you are fittingly and strongly grateful, but who in subsequent years starts wronging you by spreading mean gossip about you, or you tell the benefactor about some disappointment of yours and they can barely contain their glee about it. At this point, gratitude for the original benefits is no longer fitting and any debt of gratitude has dissipated - plausibly, because the benefactor no longer has good will towards you. As Seneca put it:

Someone who has once behaved with good will and generosity towards me, but later and on many occasions with arrogance, contempt, and cruelty, has placed me in a situation where I am just as free in regard to him as if I had not received anything; he has killed his own benefits. (Seneca 2011: 139)

But, since the sibling relationship is robust, one should to some degree still treat a sibling specially who, lamentably, is like this.

As a separate objection, consider some of the factors that determine the fittingness of gratitude and the factors that determine the strength of gratitude. Gratitude is especially fitting and ought to be especially strong when (among other factors), (i) the benefit was given intentionally as a benefit; (ii) the giving of a benefit was supererogatory for the benefactor; or (iii) the giving of the benefit imposed costs or risks on the benefactor (Blustein 1982: 177). The benefits that siblings bestow on one another during childhood largely fail to instantiate any of these 
factors. For instance, by playing with her younger brother, older sister gives him the benefit of being socialized largely unintentionally. It was a treatment that she ought to have given her brother anyway and did not impose costs or risks on her. The gratitude theory is also unable to explain why siblings, as children, ought to treat one another specially from the outset, before any benefits have been received.

\section{The friendship theory}

The friendship theory of filial piety is that "friends are motivated by love" (English 1979: 353) to seek one another's well-being and that the relationship between child and parent is friendship (English 1979), or a sui generis form of friendship (Dixon 1995: 80-82), hence children ought to seek the well-being of their parents.

As applied to siblings, the friendship theory can account for a few of the intuitive judgments noted above. It seems that friends ought to treat one another specially in an open-ended way. Again, when a friendship breaks down it seems that we often do think that we ought to repair it - but by no means always, and perhaps much less when the breakdown of the friendship was not at all due to one's own wrongdoing.

Although in a prototypical case siblings may be friends, friendship is not what accounts for the basic contours of how siblings qua siblings ought to treat one another specially, because friendship is not able to explain some of the intuitive judgments noted above:

- Non-discretionary. Friendship is the paradigm of a discretionary relationship. Although a person should not simply stop being friends with someone at the drop of a hat, one can choose to stop being friends with someone, and we typically lose friendships and gain new ones throughout life as our values and interests change and as we move from one place to another. By contrast, although we can and often do drift away from or become estranged from our siblings as adults, we do not lose our sibling relationship with them. Transferring these observations to the normative domain, we should still treat an estranged sibling specially, whereas the special treatment due an old or exfriend is much weaker.

- Robust. Friendships seem considerably less robust than the sibling relationship. If you discover that a friend has been doing wrong by you, such as by deceiving you or stealing from you, the special treatment owed to that friend is radically diminished if not altogether annulled. Again, when a friend fails to treat you specially in the ways that a friend ought to, after a period of time you are no longer required to treat them specially in any way. Again, friendships do not seem very robust in the face of non-wrongful behavior that the friends regard as being of negative value, such as voting for a disliked party or adopting a disliked lifestyle.

\section{The special goods theory}

The special goods theory of filial piety is a recent innovation by Simon Keller. Keller draws a distinction between "generic goods, which could in principle be received from anyone, and special goods, which the parent can receive from no one (or almost no one) but the child" (Keller 2006: 266). As examples of generic goods which could be received from anyone, Keller mentions things like "medical care, a 
ride to the shops" (Keller 2006: 266), and one of his examples of a special good which can be received from no one (or almost no one) but a single individual is the following:

You might value your child's keeping in touch, but not because you want to be in touch with someone and your child is someone. The good in question is the good of having your child, the one you raised, love and care about, make an effort to keep in touch. (Keller 2006: 266)

Keller gives a brief account of why adult children have a special duty to provide their parents with special goods:

The reason why you have special duties to your parents is that you are uniquely placed to provide them with these goods, and find yourself in a relationship in which they have provided (and perhaps continue to provide) special goods to you. (Keller 2006: 268)

The first clause of Kelley's sentence points towards the idea that within the typical parent-child relationship the following general principle applies: that "when you are uniquely placed to provide someone with an important good, you have a moral reason to do so" (Keller 2006: 273). The significance of the fact that one finds oneself in a relationship in which one's adult parents provide or have provided special goods to one is clarified by Keller's remarks on the conditions under which he takes there to be no filial duties.

Keller offers what I will call a mutuality condition, that one has no duty to provide a special good to one's parents:

if your parents choose not to carry out their duties towards you, make unreasonable demands, or are otherwise to blame for the deterioration of the relationship - if they disown you without good reason, for example then your duties to provide the special goods to them is mitigated or dissolved, even if you are still able to provide these. (Keller 2006: 269)

Further, Keller offers what I will call a likelihood of success condition, that one has no duty to provide a special good to the other party if, for whatever reason, being able to successfully provide it is unlikely:

[...] the children... who do not have filial duties are the ones who are not well placed to provide the special goods to the parent. Because of their utterly incompatible personalities or world-views, their sharing a destructive or dysfunctional relationship, or their respective financial and other circumstances, a parent and grown child may have very little to offer each other. (Keller 2006: 270)

So, it seems that for Keller the fact of finding oneself in a relationship with an adult parent who provides or has provided special goods serves as a good proxy for these two further conditions on filial duties.

It seems plausible that siblings do provide one another with some special goods. For instance, although it is a generic good that one's children have relationships with non-parent adults, it can be a special good that one's children have relationships with their aunts and uncles. The same seems true of siblings offering and receiving advice - due to their lifelong and involuntary association, receiving advice from a sibling can be a special good as compared with receiving advice from a friend or a therapist. 
It seems that the special goods theory of siblinghood is the best theory surveyed so far, as it seems to provide an explanation for several of the noted intuitive judgments, such as Open-ended and Permanently reduced well-being in cases of breakdown and much of Content (Keller 2006: 268). However, I suggest three criticisms of the special goods theory: 1) the special goods of siblinghood do not make a significant contribution to well-being; 2) that the special treatments of siblinghood do not all relate to the provision of special goods; and 3) that there are cases in which one sibling ought to treat another specially despite the mutuality condition and the likelihood of success condition not being met.

\section{The special goods of siblinghood do not make a significant contribution to well- being}

I agree with Keller's estimation that the special goods of the parent-child relationship make an important contribution to a person's well-being:

The goods that parenting adds to a life can be, if our ordinary attitudes are to be trusted, of enormous value... People who enjoy all good health, wealth and professional success may nevertheless feel that if they never have children then something important will be missing from their lives. (Keller 2006: 265-66)

In the same vein, Adam Swift and Harry Brighouse remark that:

People do indeed go to great lengths in order to raise children, and some consider the inability to do so as a profound blight on their lives...many regard themselves as having missed out on an experience that would have been necessary for them fully to flourish. (Brighouse and Swift 2014: 99-100)

Again, psycho-sociological findings indicate that involuntary childlessness is often negatively associated with measurable aspects of well-being, such as scores on depression, anxiety, and life-satisfaction scales (Greil, Slauson-Blevins, and McQuillan 2010: 144, 147-48).

By contrast, it seems that equivalent claims about siblinghood would be far too strong. It seems that we do not feel of only children that "something important is missing from their lives" or that they suffer from "a profound blight on their lives." Rather it seems that we think only children are just as or almost as well off as children who have siblings. Likewise, psycho-sociological findings indicate that only children do not differ from children with siblings in measurable aspects of their well-being, such as self-reported satisfaction with life as a whole, positive mood or self-esteem (Veenhoven and Verkuyten 1989), nor in their personality traits, social competence, and so forth (Mancillas 2006).

So, we might conclude that the special goods of siblinghood do not make a significant contribution to well-being. This conclusion might seem too quick, since many people who do have siblings seem to receive special goods of enormous value from their siblings. So, this presents something of a puzzle: on the one hand only children seem to be just as or almost as well off as children who have siblings, yet on the other hand children who have siblings seem to receive special goods of enormous value from their siblings.

To solve the puzzle, we can note two different senses in which a good is special, both of which are at play in Keller's discussion of filial piety, but which are not clearly distinguished. On the one hand, an action-theoretic claim addresses whom one is able to receive a good from, and in this sense generic goods are those "which 
could in principle be received from anyone" and special goods are those which can be received from "no one (or almost no one)" but one individual. On the other hand, an axiological claim considers whether some good can admit substitutes or not in its contribution to an individual's well-being, that is, whether it makes a contribution to well-being that no other good can make. As Keller said above, some people "feel that if they never have children then something important will be missing from their lives" - no amount of health or wealth or other goods can function as a substitute for the goods associated with having a child, so these goods are special rather than generic in the axiological sense.

Note that, in many cases, a good being special in the axiological sense explains why that good is special in the action-theoretic sense: the fact that your child's keeping in touch is special to you in the axiological sense is why there is some good that only your child can provide. Further, note that whether some good is special in the action-theoretic sense is in part relative to each individual - one person may be able to receive the good of "good advice" from practically anyone, another person may only be able to receive good advice from a handful of people.

So, we can solve the puzzle posed above by saying that although most of the goods that people receive from their siblings are not special in the axiological sense, many of the goods that people receive from their siblings are special for them in the action-theoretic sense. For instance, a good like "the caring companionship of an equal" that can be provided by a sibling is not special in the axiological sense compared with that provided by a good friend, but given facts about the histories of a token pair of siblings, this good may be special in the action-theoretic sense. With this distinction we can account for the plausible claim that an only child might make - "I was fine growing up and I still am because I have close friends" - and the plausible claim that someone with a sibling might make - "My sister provides me with goods that no one else can."

In light of the claim that the only child is just as or almost as well off as the child with siblings, we may conclude that the goods of siblinghood that are special in the axiological sense are so minor that they cannot ground special duties to provide these things. Being told a "home truth" by a sibling may for example really be a special good in the axiological sense as compared with being told a "home truth" by a parent or being given serious advice by a friend, but not a good that makes such a significant additional contribution to well-being that it grounds a duty to so provide it. As Keller notes, and as seems plausible, it is only when a good makes an important contribution to a person's well-being that one has a duty to provide it on that ground (Keller 2006: 273).

The defender of the special goods theory might note that, nevertheless, providing a good that is special in the action-theoretic sense only - being the only one who can provide an axiologically generic good - may impose a special duty to do so if the good makes an important contribution to a person's well-being. When you are the only one who can give a starving person food you plausibly have a special duty to do so despite the fact that "being given bread by stranger $X$ " is an axiologically generic good - pasta from stranger $Y$ or potatoes from stranger $Z$ would have served as equally good substitutes in terms of their contribution to the starving person's well-being.

In response, it seems that it is necessary to clarify in which modal register the claim is being made that a good could be received from no one but a given 
individual. Keller's own claims seem to relate to the conceptual modal register (given his use of "in principle"). In the conceptual modal register, most of the goods that siblings provide to one another are not special - as the mere conceivability of a just-as well-off only child shows, most of the goods that siblings provide can be provided by others, such as friends. In a weaker modal register like the practical modal register, it could be the case that only a token sibling could provide another token sibling with a good that makes an important contribution to their well-being; for example, your very elderly sibling could conceptually receive the good of "the caring companionship of an equal" from a strong friendship, but now it is no longer practically possible for them to acquire a strong friendship because they live in a remote area or because the local council has closed the senior social center. Here, it seems not altogether implausible that you ought to provide such a sibling with such a good if doing so is possible for you in the practical sense. But, here it seems we are no longer talking about how siblings ought to treat one another specially qua sibling, but about how you ought to treat others qua-only-person-positioned-toprovide-a-good, since on the one hand it seems that (according to the present theory) one would have a duty to provide the same good to someone who is not a sibling and, on the other hand, one would not have such a duty to one's sibling but for various highly contingent social facts (in this case, facts about the way the living arrangements and social activities of the very elderly are organized in one's locality).

The special treatments of siblinghood do not all relate to the provision of special goods

I noted my intuitive judgment that siblings ought to give one another material help in cases of severe material need. Yet, material help is not a special good in the action-theoretic sense. Material help from a sibling may be a special good in the axiological sense, but plausibly the additional non-substitutable contribution to well-being that is made because the material help is received from a sibling is not so important that it imposes a special duty. So, the special goods theory does not explain the intuitive judgment that siblings ought to give one another material help in cases of severe material need.

Cases in which one sibling ought to treat another specially despite the mutuality condition and the likelihood of success condition not being met

Consider the following case:

Andrew is the brother of Brady and Sarah. Andrew is not a very nice character, though. He shows no interest in continuing his relationship with Brady and Sarah - he ignores the sibling group-chat, he never bothers to visit them or makes plans for them to visit. Again, he neither offers them advice nor will he tolerate it from them. Again, he shows no interest in developing a relationship with Brady's or Sarah's children and stymies the efforts of Brady and Sarah at developing a relationship with his children. He doesn't help Brady and Sarah in discharging their duties of filial piety, and when Brady and Sarah fall into severe material need he doesn't help them. Brady and Sarah have no reason to expect that Andrew will ever change. 
Now, a whole novel would be needed for us to clarify every relevant feature of the case, but we will stipulate that Andrew has no justifications or excuses for acting as he does (Brady and Sarah are and always have been very nice to Andrew, Andrew's not visiting or helping Brady and Sarah were not due to other pressing concerns or lack of means, Andrew does not suffer from mental illness, and so forth. He is simply not a very nice character). Andrew abjectly fails the mutuality condition and the likelihood of success condition. On the one hand Andrew does not provide his siblings with any special goods, and on the other hand it is unlikely that they will be able to provide Andrew with any special goods. So, in the present theory, Brady and Sarah do not need to try to provide Andrew with any special goods. This, I submit, seems wrong. Since the oughts of siblinghood are not maximally robust, this is not to say that Brady ought to try to help Andrew as much as he ought to help Sarah, but the failure of the special goods theory becomes evident if we can think of any special goods that Brady and Sarah should try to give Andrew. For instance, perhaps every so often Sarah ought to make efforts to get her own children and Andrew's children together, or perhaps every so often Brady ought to make an effort at repairing the relationship by sending Andrew a thoughtful birthday present or letting Andrew know that he'd love to go fishing (Andrew's favorite pastime) with him.

In terms of the intuitive judgments noted above, the special goods theory fails to explain Robust and Non-discretionary; despite Andrew's wrongful treatment of his siblings and his best attempts to dissociate from his siblings, his siblings still ought to treat him specially in ways that they need not treat strangers.

\section{The familial belonging theory}

I suggest that the institution of the family constitutively has certain goals, such that those who are members of a token family have these goals qua family member. Family members have different roles within a family - at the least including parent and child - and different rights and duties attach to these roles, with the rights and duties being grounded by their relation to the goals of the family. Some such duties may make an action obligatory because its performance significantly advances a goal of the family, other duties may make an action impermissible because its performance significantly frustrates a goal of the family.

Goals of the family might include examples such as advancing the child's wellbeing (Blustein 1982), shaping the child's values (Page 1984), having a parent-child relationship (Brighouse and Swift 2014), or a certain continuity of identity between parent and child (Reshef 2013). In each case, we can identify duties that plausibly attach to the roles of parent and of child if the family constitutively has these goals. If a goal of the family is to advance the child's well-being, this plausibly means that parents have a right to make many decisions on their (non-adult) child's behalf and (non-adult) children have a duty to abide by these decisions. A parent might decree, "You can't hang out with James anymore, he's a bad influence," and the child's duty would be to abide by this, "Ok mom, I won't."

I will suggest one goal of the family that explains the ways in which adult siblings ought to treat one another specially. One goal of the family is for every member to feel familial belonging towards every other member. Without attempting to define 
familial belonging here - trusting that it is a familiar feeling - we can say that it is composed of dispositions towards the following: the feeling of being a part of the whole, the feeling that each part of this whole is a part of every other, the feeling that each part of the whole is a part that cannot be replaced, the feeling that being a part of this whole cannot cease, the feeling that the well-being of each part affects the well-being of every other part and of the whole; desiring that these relations be recognized by those who are its parts and those who are not, and affective states that concern these parts, the whole and their relationships (most prominently, shame or pride, closeness or alienation). I will now provide some reasons for claiming that familial belonging is indeed a goal of the family before going on to address in more detail how adult siblings treating one another as they ought in the ways described is grounded by the goal of familial belonging.

\section{Familial belonging is a goal of the family}

How can we know that every member feeling familial belonging towards every other member is a goal of the family? For one, intuitive judgment tells us that a family in which few or no feelings of familial belonging exist is not a flourishing family, and that it is not functioning as it should. For another, intuitive judgment would say that we should be less inclined to describe a community as a family if it seemed to lack this goal (plausibly, "family" is a cluster concept, such that the absence of this constitutive goal counts against something being a family even if the absence of this constitutive goal does not by itself rule out something being a family). In addition, this claim explains two things: the typical practices of parents that cultivate familial belonging during their children's childhoods, and that parents judge their well-being to be lessened by the absence of feelings of familial belonging between members of the family.

\section{Typical practices of parents to cultivate familial belonging}

Familial belonging as a goal of the family is indicated by the practices of parents who cultivate familial belonging between their children during their childhoods. Parents encourage their children to play together, to spend time together, or to develop shared hobbies, e.g. "Show him how to play Red Alert with you." Parents encourage their children to delight in one another's achievements and to sympathize with one another's hardships - such as when they make sure that littlesister is there to watch your piano recital, e.g."That's your brother! Aren't you proud?" or encourage big-brother to treat you sympathetically whilst your leg is in a cast. Again, parents develop unique family traditions that give siblings a shared set of memories, and parents encourage siblings to understand themselves by reference to one another, e.g. "You are so reserved with strangers, just like your sister! But she has a rebellious streak that you don't." Imagine the case of the child who did not feel familial belonging towards his siblings, who thought of them as "mom and dad's other kids" rather than as his brothers and sisters, who did not feel sad about their hardships, and so forth. Such a child's parents would be horrified at his feelings and think that they were in need of correction. All of these typical practices can be understood and explained as ways in which parents promote the goal of familial belonging. Parents also cultivate familial belonging for each other and between themselves and their children, such as when one parent might say to 
the other, "I know your Saturdays are sacred, but you should take little Sarah out trainspotting with you, it would be a good way for you two to bond."

Parents judge their well-being to be diminished by the absence of feelings of familial belonging between members of the family

In general, it seems that failing to achieve a goal lessens a person's well-being, including goals one has by virtue of occupying a certain role. I suggest that this is a good way to understand the judgments of parents about their diminished wellbeing in cases where feelings of familial belonging are absent between their children. Consider these comments made in response to the article "What to Do When Your Adult Kids Keep Fighting," written for a popular audience:

Gosh, I have to say at least I don't feel alone in this cutting pain that I feel about my two adult daughters fighting over and over. Thank you all for sharing. My two girls have a pattern of fighting as adults for the past 10 years now. They are 35 and 40. It hurts me so much that although I am a single parent living 3000 miles away from them, I don't want to visit anymore. It breaks my heart to have one daughter want to spend time with only me, pick me up and I have to leave her sister alone.

I am not the parent, but the older sister. My brother and sister have not spoke [sic] or been in the same room for over four years. This is killing my parents. I have tried to explain to them what they are doing to all of us.

He [the father] is completely heart broken [sic] that they [the children] do not get along, and it breaks my heart to see him so distraught. He's at the point now, that he doesn't want family gatherings anymore, because of the tension, bickering and judgemental behaviour. We simply adore our children and have tried to raise them close to each other, but we feel like we have failed. (Lener 2018)

These comments illustrate that breakdown and estrangement between adult siblings - surely inimical to feelings of familial belonging between adult siblings damage the well-being of their parents. Here, it seems that the siblings are treating one another (fighting, not speaking, bickering) in ways that frustrate their feelings of familial belonging for one another and likewise split the feelings of familial belonging for other family members, damaging the feeling of the wholeness of the family. It seems plausible that less extreme cases - such as when adult siblings fail to help one another in cases of severe material need or neglect to develop relationships with their nieces and nephews - would also, albeit to a lesser degree, damage the well-being of parents by frustrating the achievement of one of the goals that parents have as members of the family.

Psycho-sociological research shows that good relations between parents and their adult children is positively associated with measurable aspects of the parents' well-being (Ward 2008). Unfortunately, it seems that no psycho-sociological research has directly investigated the association between poor adult sibling relations and measurable aspects of their parent's well-being, so I rely on these anecdotal reports. 


\section{The goal of familial belonging and special treatment between siblings}

Since familial belonging is a complex mix of affective states, and since affective states are not under direct voluntary control, it seems clear that there can be no duty to feel familial belonging. Nevertheless, our affective states can be indirectly influenced by our actions, and since actions are under our direct voluntary control they can be regulated by duties (Landau 2004). The special ways in which adult siblings ought to treat one another can be understood as ways in which adult siblings can avoid the frustration of, or promote, feelings of familial belonging.

- Content. Here it seems that Continuation of the relationship facilitates the goal of familial belonging by helping to keep open the space within which feelings of familial belonging can develop - such as the two estranged brothers who typically share only superficial chit-chat and find their feelings of familial belonging reawakened at a family reunion, which would not have happened if they had not attended. Cooperation in discharging duties of filial piety gives adult siblings a shared object of concern by activating and cultivating their feeling of being parts of the whole by attending to another part together. Material help in severe material need serves as a way in which siblings can activate and cultivate the feeling that their well-being is in part constituted by the well-being of the other members of the familial community. Offering and receiving advice activates and cultivates an ongoing interest in one another's lives. Relationship with their children is a way in which siblings affirm their feelings of familial belonging for one another whilst also affirming their sibling's belonging in a new family.

- Non-discretionary. Since one cannot choose what treatment does or does not contribute to the goal of familial belonging, how siblings ought to treat one another is not at their discretion.

- Open-ended. Since siblings treating one another as they should continually contributes to the goal of familial belonging, there is no particular point at which siblings have "completed" treating each other as they should. The familial community can survive the deaths of the parents since siblings with deceased parents are clearly still family, so the death of the parents does not fundamentally alter how siblings ought to treat one another.

- Permanent regret in cases of breakdown. Since the breakdown of the relationship between siblings poses an ongoing frustration of the goal of familial belonging, such breakdowns ought to engender ongoing regret for the siblings.

- Permanently reduced well-being in cases of breakdown. Failing to achieve a goal reduces a person's well-being, and since siblings retain this goal of the familial community by continuing to be family members, breakdown in the relationship between siblings permanently reduces their well-being so long as the breakdown lasts.

- Repair. In this theory, repair can be understood to encompass actions that attempt to remove factors that are frustrating the achievement of the goal of familial belonging - e.g. one can attempt to get back in contact with a sibling, or try to better understand what led to the breakdown of the relationship, and so forth. Likewise, since other members of the family have the goal of familial belonging, the breakdown in the relationship between two siblings reduces the well-being of their parents and other siblings by damaging the feeling of the 
wholeness of the family - hence the plausible thought that two siblings should repair their relationship "for mom and dad."

- Robust. Since siblings should have the goal of familial belonging in mind, the wrong that one sibling does to another or the bad behavior that they display is not the only factor that determines how they should be treated. By analogy, if colleague Clive wrongs colleague Diana in some way - such as handing in assignments very late for no good reason, thereby disrupting Diana's workflow - it does not mean that Diana's special treatment of colleague Clive should change drastically, e.g. deciding not to include Clive in important e-mail chains, because Diana's special treatment of Clive is largely a matter of her role-based responsibilities, grounded in the goals of the company.

So, the intuitive judgments I made at the outset are explained well by the familial belonging theory of what grounds special treatment between siblings, which in itself is a reason to accept the familial belonging theory.

\section{Clarifications}

What about cases of bad or abusive parents, who did not cultivate feelings of familial belonging between every member of the family? Should the children of such parents treat their siblings in the ways described?

The goal of familial belonging is held by parents whether they desire to achieve it or not. By analogy, a corrupt politician has goals qua a political office holder even if such a politician has no desire to achieve the goals, and such a politician damages his own well-being by having such goals and not achieving them. In both cases, appropriately blaming the person who inhabits the role for performing or not performing a certain action can be explained by the fact that the person inhabiting the role has certain goals qua inhabitor of that role.

So, if the parents of some siblings were bad or abusive, it does not mean that the siblings do not also have the goal of familial belonging or that they need not treat one another specially in the ways described. If anything, it seems that in such situations adult siblings ought to pay more attention to cultivating feelings of familial belonging with one another, given the absence of, or difficulties with, feelings of familial belonging towards or from their parents.

It seems that the feelings of familial belonging that siblings hold toward one another are special goods in the axiological sense, i.e. ones that make a nonsubstitutable contribution to well-being as compared with, say, the feelings of belonging within a friendship group, so isn't this theory just a subspecies of the special goods view?

It is indeed a special good in the axiological sense when a family achieves its goal of having feelings of belonging between every member of a family. This good adds to the well-being of each member of the family in a way that cannot be substituted by other goods. But there is a difference between the claim that the special treatments of siblings are grounded by the provision of a special good and the claim that the special treatments of siblings are grounded by the goal of familial belonging. This difference is brought out by the case in which provision of a special good is not possible. As Keller noted, in his theory someone who is not able to provide a special 
good has no duty to do so: "[...] the children... who do not have filial duties are the ones who are not well placed to provide the special goods to the parent" (Keller 2006: 270 cf. 271-272). The present theory is more Aristotelian in its view of the relationship between the right and the good: the sibling who knows that they will not in fact be able to provide their sibling with a special good by treating them as they should is still an excellent sibling for having the disposition to treat them in that way, because they still have the goal of familial belonging. In the case of Andrew, Brady and Sarah related above, if it were the case that Brady did make attempts at repair with Andrew and Sarah did not, there is a sense in which Brady is the better sibling even though he does not provide Andrew with any special good and does not actually achieve the goal of familial belonging. By analogy, a good heart is one which serves well the proximate goal of pumping blood even if the service of this proximate goal is in vain with respect to the ultimate goal of sustaining life because the organism's other organs have failed. Cultivating feelings of familial belonging between siblings provides them and other family members with a special good, but this theory is not directly founded on the idea that two siblings ought to cultivate feelings of familial belonging toward one another simply because this provides them with a special good. The familial belonging theory can make sense of what it means to be a good sibling even when no special goods are provided.

\section{Acknowledgements}

Thanks to the two anonymous reviewers for their insightful comments and to the editors. Thanks to Eric Brown, Jason Byas, Victoria Grace, Nicholas Sars, David Shoemaker, Geoffrey Weiss, and participants at the Tulane Philosophy Club for their valuable comments on an earlier version of the paper. Thanks to my siblings Damaris, Vivian, and Daniel.

\section{References}

Blustein, Jeffrey. 1982. Parents and Children: The Ethics of the Family. Oxford: Oxford University Press.

Brighouse, Harry, and Adam Swift. 2014. Family Values: The Ethics of Parent-Child Relationships. Princeton, NJ: Princeton University Press. https://doi.org/ $10.1515 / 9781400852543$

Dixon, Nicholas. 1995. The Friendship Model of Filial Obligations. Journal of Applied Philosophy 12(1): 77-87. https://doi.org/10.1111/j.1468-5930.1995. tb00121.x

English, Jane. 1979. What Do Grown Children Owe Their Parents. In Having Children: Philosophical and Legal Reflections on Parenthood, eds. Onora O’Neill and William Ruddick. New York: Oxford University Press, 351-56.

Greil, Arthur, Kathleen Slauson-Blevins, and Julia McQuillan. 2010. The Experience of Infertility: A Review of Recent Literature. Sociology of Health \& Illness 32(1): 140-62. https://doi.org/10.1111/j.1467-9566.2009.01213.x

Keller, Simon. 2006. Four Theories of Filial Duty. Philosophical Quarterly 56(223): 254-74. https://doi.org/10.1111/j.1467-9213.2006.00441.x 
LaFollette, Hugh. 2017. Kinship and Intimacy. Etikk $i$ Praksis 11(1): 33-40. https://doi.org/10.5324/eip.v11i1.2244

Landau, Iddo. 2004. An Argument for Marriage. Philosophy 79(3): 475-81. https://doi.org/10.1017/S0031819104000385

Lener, Michele. 2018. What to Do When Your Adult Kids Keep Fighting. The Hartford Extra Mile. https:/extramile.thehartford.com/family/parenting/ arguing-adult-kids/ (December 16, 2019).

Mancillas, Adriean. 2006. Challenging the Stereotypes About Only Children: A Review of the Literature and Implications for Practice. Journal of Counseling and Development 84(3): 268-75. https://doi.org/10.1002/j.1556-6678.2006. tb00405.x

Page, Edgar. 1984. Parental Rights. Journal of Applied Philosophy 1(2): 187-203. https://doi.org/10.1111/j.1468-5930.1984.tb00002.x

Reshef, Yonathan. 2013. Rethinking the Value of Families. Critical Review of International Social and Political Philosophy 16(1): 130-50. https://doi.org/ 10.1080/13698230.2012.680745

Seneca, Lucius Annaeus. 2011. On Benefits. Chicago: University of Chicago Press.

Veenhoven, Ruut, and Maykel Verkuyten. 1989. "The Well-Being of Only Children." Adolescence 24(93): 155-66.

Walker, A. D. M. 1981. Gratefulness and Gratitude. Proceedings of the Aristotelian Society 81: 39-55. https://doi.org/10.1093/aristotelian/81.1.39

Ward, Russell. 2008. Multiple Parent-Adult Child Relations and Well-Being in Middle and Later Life. The Journals of Gerontology 63(4): S239-47. https://doi.org/10.1093/geronb/63.4.S239 